\title{
laborhifórico
}

ISSN 2359-6910

https://revistas.ufrj.br/index.php/lh/

FONTES PRIMÁRIAS

Recebido em 10 de dezembro de 2020

Aprovado em 5 de março de 2021

\section{Requerimento do promotor do Santo Ofício da Inquisição de Goa solicitando o trabalho das cartas régias dos anos de 1700 e 1701}

DOI: https://doi.org/10.24206/lh.v7i2.40029

Bárbara Franco Cardoso

Possui Graduação em Pedagogia (1999 - Universidade Salgado de Oliveira) e Letras (2003 - Universidade Federal Fluminense), Pós-Graduação Lato Sensu em Docência do Ensino Básico pelo Programa de Residência Docente do Colégio Pedro II (2017 -Colégio Pedro II) e Stricto Sensu (Mestrado) em Estudos da Linguagem (2020 - Universidade Federal Fluminense). Já atuou como Professora de Língua Espanhola na Prefeitura Municipal de São Gonçalo e na Fundação de Apoio à Escola Técnica (FAETEC). Atualmente é professora de Língua Portuguesa na Prefeitura Municipal de São Gonçalo e de Língua Espanhola na Secretaria de Educação do Estado do Rio de Janeiro.

E-mail: profeespanol@gmail.com ORCID: https://orcid.org/0000-0002-8503-145X 


\section{RESUMO}

Este texto tem como propósito apresentar a transcrição e a edição do documento pertencente ao acervo de manuscritos da Fundação Biblioteca Nacional que exibe o pedido do promotor do Santo Ofício da Inquisição de Goa ao rei de Portugal, em 1706, no qual deseja o traslado das cartas régias redigidas no início do século XVIII acerca do requerimento que os pagãos realizaram para obter informações sobre a forma mais adequada para que pudessem realizar seus ritos matrimoniais. Partindo de uma pesquisa de ordem paleográfica, para a realização deste trabalho, utilizaram-se Noções de Paleografia e de Diplomática de Ana Regina Berwanger e João Eurípedes Franklin Leal, As Normas Técnicas Abreviaturas: manuscritos dos séculos XVI ao XIX de Maria Helena Ochi Flexor e Abreviaturas Paleográficas Portuguesas de Eduardo Borges Nunes.

Palavras-chave: Inquisição de Goa. Século XVIII. Manuscrito. Transcrição. Edição. 


\section{Apresentação}

O documento selecionado para a transcrição pertence à coleção de manuscritos da Fundação Biblioteca Nacional ${ }^{1}$. Trata-se da solicitação realizada, em 1706, pelo promotor do Santo Ofício da Inquisição de Goa em prol do traslado das cartas régias dos anos de 1700 e 1701 acerca do requerimento que os gentios fizeram sobre o modo pelo qual poderiam realizar seus casamentos.

Por ser um antigo estado do império português, Goa serviu de cenário para a inquisição que foi criada em 1560, após anos de discussão sobre a importância de sua instauração. Nesse local, a atuação do Tribunal do Santo Ofício refletiu, precisamente, na superstição, no islamismo e na gentilidade, além da heresia e do judaísmo que já faziam parte deste território indiano.

Quem recebeu maior destaque nesse período inquisitório foi o promotor João Delgado Figueira que também foi inquisidor do Tribunal do Oriente, de Évora, de Lisboa e conselheiro letrado do Conselho Ultramariano. Segundo Francisco Bethencourt (2009), a carreira dos inquisidores do tribunal de Goa é restrita, muitas vezes, ao clérigo das ordens religiosas instaladas na capital do Estado da Índia, sobretudo dominicanos e jesuítas. Contudo poderia ocorrer a possibilidade de esses funcionários pertencerem ao próprio reino e não serem oriundos de nenhuma ordem religiosa.

Ao se fazer uma investigação sobre a formação dos funcionários do tribunal indiano, jamais se obteve muita coisa, pois as fontes inquisitoriais nunca disponibilizaram esse tipo de informação, ou até mesmo quando se conseguia algo, não era nada preciso, podendo ser considerado confuso. O curioso é que, segundo António Baião (1878-1961)², tampouco foi encontrado o processo de habilitação que pudesse fornecer informações verdadeiras sobre o nascimento de João Delgado Figueira, sua filiação, sua formação, embora essas informações fossem disponibilizadas sobre outros inquisidores. Somente se sabe que esse homem era bem visto pela corte portuguesa, pois antes de assumir o cargo de inquisidor, sendo apenas promotor, foi apresentado e recomendado pelo Conselho Geral aos inquisidores de Goa. Como realizava seu trabalho sempre com dedicação e eficiência, não deixava de ser elogiado pelos seus superiores, e, com isso, conseguiu alcançar o cargo de inquisidor. Foi esse funcionário da corte quem redigiu o documento enviado à Santa Sé, em 1619, contra os ritos gentílicos e as práticas protegidas pelo jesuíta Roberto de Nobili (1577-1656), como também participou de uma junta de teólogos formada pelo governador Fernão de Albuquerque (1540-1623), que teve como propósito a

${ }^{1}$ Disponível em: http://acervo.bndigital.bn.br/sophia/index.asp?codigo_sophia=30515. Acesso em 10 dez 2020.

${ }^{2}$ António Eduardo Simões Baião foi um historiador e pedagogo português, sendo mais conhecido como António Baião. Publicou inúmeros artigos sobre a História de Portugal, tendo como destaque a historiografia da Inquisição em Portugal e em seus domínios coloniais. 
discussão sobre os ritos gentílicos e, também, a origem da decisão a respeito da proibição das festas de casamento dos hindus ocorridas em Goa, mediante o alvará de 31 de janeiro de 1620.

Vale ressaltar que João Delgado Figueira, no início de seu trabalho como promotor, foi a peça chave de um desentendimento entre a Inquisição de Goa e a Companhia de Jesus. O fato que levou a tal discórdia foi a discussão sobre os ritos gentílicos defendidos pelo Padre Roberto Nobili, visto que, para esse eclesiástico, essas cerimônias eram somente sinais inofensivos e exteriores à fé católica. E, com isso, as conversões realizadas por esse jesuíta, no Malabar, geravam suspeitas referentes à sua validade.

Como João Delgado Figueira exercia o seu trabalho com muito esmero, não costumava deixar falhas, principalmente quando era a respeito dos gentios. Então, como estava realizando investigações sobre esse povo pagão, uma de suas tarefas foi solicitar o trabalho das cartas régias dos anos $1700 \mathrm{e}$ 1701 acerca do requerimento que essas pessoas fizeram para saberem como deveriam realizar seus casamentos.

O Tribunal da Inquisição de Goa foi extinto em 1774, sob ação do Marquês de Pombal (secretário de Estado do Reino), sendo instaurado após 4 anos, em 1778, e definitivamente revogado em 1812 mediante um decreto régio. Cabe salientar que, logo após sua primeira extinção, seu arquivo foi enviado a Lisboa e depois retornado a Goa, assim que a inquisição foi restabelecida no local. E, depois da abolição definitiva, uma grande parte dessa documentação foi incinerada, além de sofrer bastante com o clima da região (devido à umidade) e o desleixo advindo dos ministros.

\section{Normas de Transcrição e edição utilizadas}

(1) A transcrição foi realizada mediante as normas disponíveis em Noções de Paleografia e de Diplomática de Ana Regina Berwanger e João Eurípedes Franklin Leal;

(2) Para se obter uma compreensão sobre abreviaturas, realizou-se uma pesquisa nas obras de Maria Helena Ochi Flexor (Abreviaturas: manuscritos dos séculos XVI ao XIX) e de Eduardo Borges Nunes (Abreviaturas Paleográficas Portuguesas);

(3) As abreviaturas consideradas de fácil reconhecimento foram mantidas;

(4) Usou-se uma interrogação entre colchetes após de uma palavra que gerou dúvidas ao transcrevê-la; 
(5) Para sinalizar que uma palavra estava danificada no documento transcrito, utilizou-se a expressão "corroída" entre colchete e grifada mediante a referência aproximada do seu número;

(6) A ortografia das palavras foi completamente mantida como é apresentada no documento original;

(7) A pontuação foi preservada em todo documento;

(8) O sinal de nasalização ou til com o valor de $m$ foi respeitado;

(9) A divisão paragráfica do documento original foi considerada;

(10) A edição justalinear (a separação entre linhas) foi preservada. 


\section{Fac-símiles}

Imagem 01 - f. 1r: Original - Requerimento do promotor do Santo Ofício da Inquisição de Goa - 1706

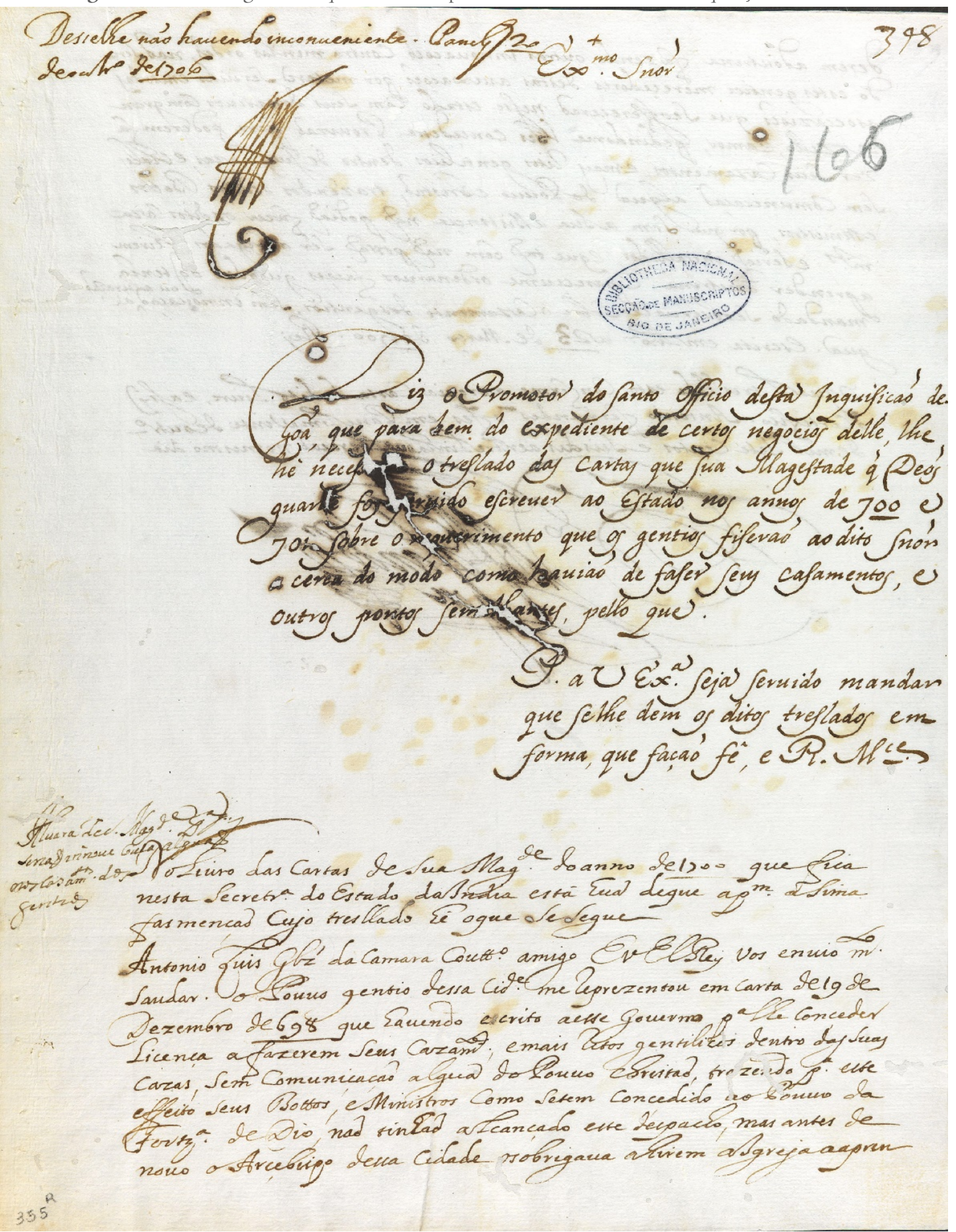

Fonte: Biblioteca Nacional, 2020. 
Imagem 02 - f. 1v: Original - Requerimento do promotor do Santo Ofício da Inquisição de Goa - 1706

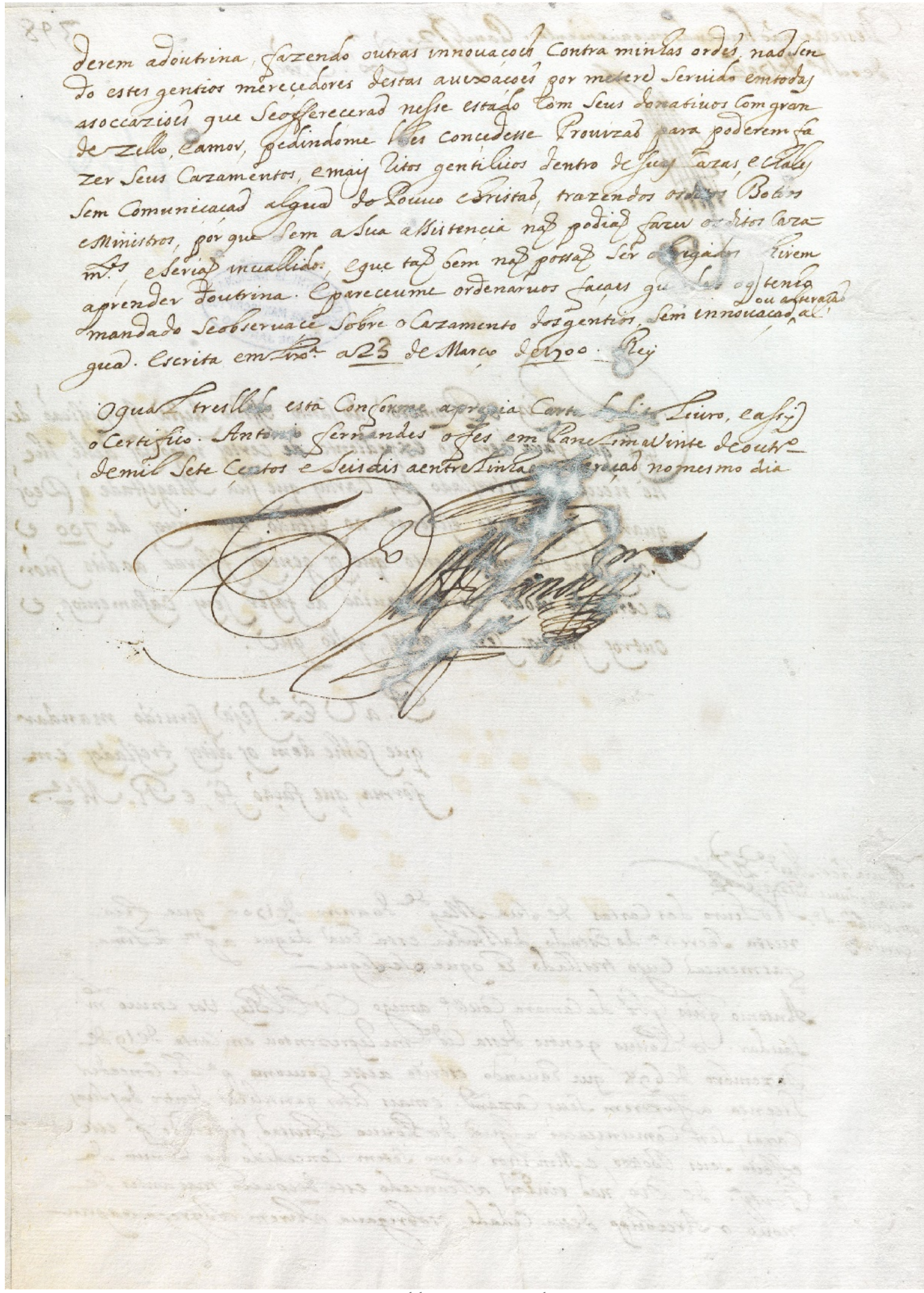

Fonte: Biblioteca Nacional, 2020. 


\section{Edição}

\section{Requerimento do promotor do Santo Ofício da Inquisição de Goa solicitando o treslado das cartas régias dos anos de 1700 e 1701, sobre o requerimento que os gentios fizeram acerca do modo de havião de fazer seus casamentos}

[fol. 1r]

Diz o Promotor do Santo Offício desta Inquisiçaõ de Goa que para bem do expediente de certos negocios delle, lhe, hè necessário o treslado das cartas que Sua Magestade que Deos guarde foi [servido?] escrever ao Estado nos annos de $700 \mathrm{e}$ 701 sobre o requerimento que os gentios fizeraõ ao dito senhor acerca do modo como haviaõ de fazer seus casamentos, e outros pontos semelhantes, pello que.

\footnotetext{
Para a Vossa Excelência seja servido mandar que lhe dem os ditos treslados e em forma que façam fé, e R. M ${ }^{\text {ce }}$
}

No livro das cartas de sua Magestade do ano de 1700 que fica Nesta Secretaria do Estado das Índias está hũa de que aproxima faz menção cujo treslado hé o que se segue Antonio Luis Glz da Camara Coutto amigo EVELRey vos envio muito Saudar o Pouus gentio dessa cide ${ }^{\text {de }}$ me Representou em carta de 19 de Dezembro de 698 que havendo escrito a esse Governo $\mathrm{p}^{\mathrm{a}}$ lhe conceder Licença a fazerem seus cazam ${ }^{\text {tos }}$, e mais atos gentílicos dentro das suas cazas, sem comunicação alguma do [Pouuo ?] Cristão, trazendo $\mathrm{p}^{\mathrm{a}}$ esse effeito seus Bottos, a Ministros como se tem concedido ao [Pouuo ?] da Forz ${ }^{\mathrm{a}}$, de Dio, não sintaõ alcançado esse despacho, mas antes de novo o Arcebispo dessa cidade [nobrigaua ?] a hirem a Igreja a apren 
[fol. 1v]

derem a doutrina, fazendo outras inovações contra minhas ordens não sen do estes gentios merecedores destas acusações por me tere servido em todas as ocasiões que se ofereceraõ nesse estado com seus donatiuos com gran de zello, e amor, pedindome lhes concedesse permizaõ para poderem fa zer seus cazamentos, e mais Ritos gentilicos dentro de suas cazas e [ilegível] sem comunicação alguma do [Pouuo ?] Cristão, trazendo os [ditos ?] Bottos e Ministros, porque sem a sua assistência não podiaõ fazer os [ditos?] cazamentos, seriaõ invallidos, e que taõ bem não possaõ ser obrigados a hirem aprender doutrina. E pareceume ordenar uos façaes guardar_o que tenha mandado de observação sobre o cazamento dos gentios, sem inovação al gũa. Escrita em $\operatorname{Lix}^{\mathrm{a}}$ a 23 de março de 1700. Rey

O qual tresllado está conforme apre[?]a a Carta [do dito?] Livro, e assy o certifico. Antonio Fernandes o fes em Panelim a vinte de outubro de mil setecentos e seis dis a entre linha [corroída 1 palavra] no mesmo dia. 


\section{Referências bibliográficas}

BERWANGER, Ana Regina; LEAL, João Eurípedes Franklin. Noções de Paleografia e de Diplomática. $3^{a}$ edição. Santa Maria: Editora da UFSM, 2008.

BIBLIOTECA NACIONAL. Requerimento do promotor do Santo Ofício da Inquisição de Goa solicitando o treslado das cartas régias dos anos de 1700 e 1701, seus casamentos. Inquisição de Goa. Manuscritos. Disponível em:

http://objdigital.bn.br/objdigital2/acervo_digital/div_manuscritos/mss1352114/mss1352114_1 66.pdf, 1706. Acesso em: 20 out. 2020.

FEITLER, Bruno. O Secreto do tribunal indiano da Inquisição portuguesa: entre Goa, Lisboa e Rio de Janeiro. São Paulo: UNIFESP, 2018.

FLEXOR, Maria Helena Ochi. Abreviaturas: manuscritos do séculos XVI ao XIX. Rio de Janeiro: Arquivo Nacional, 2008.

NUNES, Eduardo Borges. Abreviaturas Paleográficas Portuguesas. 3a edição. Lisboa, 1981.

TAVARES, Célia Cristina da Silva. Inquisição ao avesso: a trajetória de um inquisidor a partir dos registros da visitação ao Tribunal de Goa. Topoi - Revista de História - Vol. 10 - n. ${ }^{0}$ 19. Rio de Janeiro: UFRJ, 2009. 